\title{
Attenuation of the cardiovascular and metabolic complications of obesity in CD14 knockout mice
}

\author{
Roberto Roncon-Albuquerque Jr. ${ }^{a}$, Mónica Moreira-Rodrigues ${ }^{\mathrm{b}}$, Bernardo Faria ${ }^{\mathrm{a}}$, Andrea P. Ferreira ${ }^{\mathrm{c}}$, \\ Cátia Cerqueira $^{\mathrm{b}}$, André P. Lourenço ${ }^{\mathrm{a}}$, Manuel Pestana ${ }^{\mathrm{b}}$, Pedro von Hafe ${ }^{\mathrm{d}}$, Adelino F. Leite-Moreira ${ }^{\mathrm{a}, *}$ \\ a Department of Physiology, Cardiovascular Research \& Development Unit, Faculty of Medicine, University of Porto, Portugal \\ b Department of Nephrology, Nephrology Research \& Development Unit, Faculty of Medicine, University of Porto, Portugal \\ c Department of Microbiology, Superior School of Biotechnology of the Catholic University, Porto, Portugal \\ ${ }^{\mathrm{d}}$ Department of Medicine, Cardiovascular Research E' Development Unit, Faculty of Medicine, University of Porto, Portugal
}

\section{A R T I C L E I N F O}

\section{Article history:}

Received 13 December 2007

Accepted 29 July 2008

\section{Keywords:}

CD14

CD14 knockout mice

Metabolic syndrome

Obesity

Toll-like receptors

\begin{abstract}
A B S T R A C T
Aims: Although toll-like receptors (TLR) are known to mediate the metabolic complications of obesity, the mechanisms underlying its activation remain largely unknown. The present study analyzed a model of dietinduced obesity in mice lacking the TLR4/TLR2 co-receptor CD14.

Main methods: Six-week-old male mice lacking CD14 $(n=16)$ were allocated to either a control diet or a highfat high-simple carbohydrate diet ( $5.4 \mathrm{kcal} / \mathrm{g} ; 35 \%$ fat; 35\% sucrose), and compared with C57BL/6 (WT; $n=15$ ) controls. After 12 weeks, body composition, basal sympathetic activity, non-invasive blood pressure and glucose tolerance were evaluated. Hepatic and adipose tissues were collected for mRNA quantification, histology and LPS incubation.

Key findings: In both WT and CD14 knockout mice, obesity was accompanied by TLR2 and TLR4 upregulation. However, obese mice lacking CD14 presented decreased lipid and macrophage content in hepatic and adipose tissues, lower urinary levels of noradrenaline, decreased systolic blood pressure, reduced fasting plasma glucose and blunted glucose intolerance, compared with obese WT group. In the presence of exogenous SCD14, adipose tissue incubation with LPS-induced TLR2 and TNF- $\alpha$ upregulation in both WT and CD14 knockout obese mice.

Significance: In our model of diet-induced obesity, mice lacking CD14 showed lower adiposity and hepatic steatosis, improved glucose homeostasis, blunted sympathetic overactivity and reduced blood pressure elevation. This was observed in the presence of preserved TLR4 and TLR2 gene expression, and intact TLR4 signaling pathways. These results suggest that CD14-mediated TLR activation might contribute to the cardiovascular and metabolic complications of obesity.
\end{abstract}

(C) 2008 Elsevier Inc. All rights reserved.

\section{Introduction}

Toll-like receptors (TLRs) recognize conserved pathogen-associated molecular patterns (PAMPs) and play a critical role in innate immune system activation in response to invading microorganisms (Akira, 2003). Signaling through TLR2 and TLR4 is mediated by CD14, a co-receptor found in two forms: a 50 to $55 \mathrm{kD}$ glycosylphosphatidylinositol-anchored membrane protein (mCD14), expressed only in myeloid cells, and a monocyte- or liver-derived soluble serum protein that lacks the anchor (sCD14) (Kirschning et al., 1998; Pugin et al., 1994; Wright et al., 1990; Yang et al., 1998). Both protein forms are critical for signal transduction, with sCD14 conferring sensitivity to cells lacking mCD14. Although a variety of ligands can be recognized

\footnotetext{
* Corresponding author. Al. Prof. Hernâni Monteiro, 4200-319, Porto-Portugal. Tel.: +351 22 5513644; fax: +351225513646.

E-mail address: amoreira@med.up.pt (A.F. Leite-Moreira).
}

by CD14 (e.g. bacterial lipopolysaccharide (LPS), mycobacterial lipoarabinomannan (LAM)), subsequent TLR-mediated cell activation occurs in a ligand specific manner (Means et al., 1999).

Obesity is a state of chronic low-grade inflammation associated with an array of cardiovascular and metabolic complications (Semenkovich, 2006). Recent studies have proposed several causal links between TLR signaling and the metabolic complications of obesity. Firstly, TLR4 expression has been consistently demonstrated in adipocytes being upregulated in fat tissues of $d b / d b$ mice (Lin et al., 2000), and TLR4 activation has been shown to induce insulin resistance, both in vitro and in vivo (Song et al., 2006). Secondly, in a mouse model of obesity, exposure to a high-fat diet during 4 weeks induced an increase of plasma LPS concentration by 2-3 times, a threshold defined as 'metabolic endotoxemia' (Cani et al., 2007). Finally, nutritional fatty acids, whose circulating levels are often increased in obesity, have also been shown to activate TLR signaling in adipocytes and macrophages (Lee and Hwang, 2006). The expression 
of inflammatory genes such as COX-2 or iNOS induced by saturated fatty acid was blocked by a dominant-negative mutant of TLR4 or TLR2, while various unsaturated fatty acids suppressed NFKB activation induced by the TLR4 agonist LPS (Lee et al., 2003). It remains, however, to be established, the relative contribution of 'metabolic endotoxemia' and nutritional fatty acids in the TLR-mediated metabolic complications of obesity. Furthermore, data is lacking regarding the impact of TLR activation on the cardiovascular complications of obesity such as hypertension.

To further clarify the mechanisms underlying TLR activation in obesity, we studied the effect of a high-fat high-simple carbohydrate (HFHSC) diet on CD14, TLR2 and TLR4 gene expression profile, as well as on LPS-induced TLR4 activation. Furthermore, the effects of the HFHSC diet on body composition, basal sympathetic activity and systolic blood pressure, glucose homeostasis and hepatic steatosis were compared in C57BL/6 control and CD14 homozygous null mice.

\section{Materials and methods}

Animal experiments were performed according to the Portuguese law on animal welfare and conform to the National Institutes of Health Guide for the Care and Use of Laboratory Animals (NIH. Pub. No. 85-23, Revised 1996). Five-week-old male C57BL/6 mice (WT; $n=15)$ and CD14 mutant bred in a C57BL/6 background (CD14 $\left.{ }^{-/-}, n=16\right)$ male mice were purchased from The Jackson Laboratory (Bar Harbor, Maine, USA). Animals were housed in groups of 5 per cage in a controlled environment under 12:12 h light-dark cycle, at a room temperature of $21{ }^{\circ} \mathrm{C}$, with a free supply of water. Mice were allowed 1 week of adaptation to laboratory conditions before entering the experiments.

At six weeks of age animals were allocated to either a control diet (Teklad LM-485 Mouse/Rat Sterilizable Diet) with $4.1 \mathrm{kcal} / \mathrm{g}$ composed of $5 \%$ fat, $54 \%$ carbohydrate (ground corn), $19 \%$ protein, $5 \%$ fiber, $0.31 \%$ sodium and $0.85 \%$ potassium (WT, $n=7 ; \mathrm{CD}_{14}{ }^{-/-}, n=8$ ), or a high-fat high-simple carbohydrate diet (HFHSC; Diet F2685; BioServe) with $5.4 \mathrm{kcal} / \mathrm{g}$ composed of $35 \%$ fat (lard), 35\% simple carbohydrate (sucrose), $20 \%$ protein, $0.1 \%$ fiber, $0.39 \%$ sodium and $0.56 \%$ potassium (WT, $n=8 ; \mathrm{CD}_{14^{-1-}}, n=9$ ). Body weight, food and water ingestion were measured weekly throughout the study. This experimental model has been previously shown to induce obesity, type 2 diabetes mellitus and hypertension in C57BL/6 mice (Mills et al., 1993).

After 12 weeks, non-invasive blood pressure was recorded and glucose tolerance and insulin resistance tests were performed (see below). Mice were then placed in metabolic cages (Tecniplast, Buguggiate-VA, Italy) and $24 \mathrm{~h}$ urine was collected for noradrenaline quantification (see below). Finally, animals were sacrificed by sodium pentobarbital overdose, the right tibial length was measured, liver, right gastrocnemius and right gonadal fat pad were weighed, and tissue samples were extracted for incubation tests, mRNA and triglyceride quantification and histology. Subcutaneous fat samples were collected from the gonadal fat pad and visceral fat samples were extracted from mesenteric adipose tissue. The proportional weight of the gonadal fat pad (PWGFP) was used as an estimate of total body fat. The PWGFP is defined as the right gonadal fat pad weight in percentage of total body weight. This has been previously shown to closely correlate with the direct measurement of body fat in normal and obese mice (Rogers and Webb, 1980).

\section{Blood pressure measurements in awake mice}

Systolic blood pressure was assessed in awake animals using a photoelectric tail-cuff pulse detector (LE 5000, Letica). From 09h00 to $13 \mathrm{~h} 00$, mice were sited into a semicylindrical container placed in a temperature control box at $36-37{ }^{\circ} \mathrm{C}$. Animals were previously conditioned to the restrainer by repeating inflation-deflation cycles for $\sim 30$ min every 2 weeks from the start of the experimental protocol. Before measurements, animals were conditioned to the restrainer by repeating inflation-deflation cycles for $15 \mathrm{~min}$. At 12 weeks, a minimum of five reliable systolic blood pressure measurements were obtained for each animal and averaged.

\section{Glucose tolerance and insulin resistance tests}

Glucose tolerance tests were carried out at $22 \mathrm{~h} 00$ after a 14 -h fast through a single intraperitoneal injection of dextrose in water $(1.0 \mathrm{~g} / \mathrm{kg})$. Blood glucose concentration was measured before and 15, 30, 45, 60, 90, 120 and $150 \mathrm{~min}$ after injection using a blood glucose meter (Freestyle Mini $^{\mathrm{TM}}$ system). Insulin resistance was tested after a $6 \mathrm{~h}$ fast through a single intraperitoneal injection of insulin, $1.5 \mathrm{U} / \mathrm{kg}$ (Actrapid ${ }^{\circledR}$ Novo Nordisk). Measurements were made before and 15, 30, 45, 60 and 90 min after injection.

\section{4-h urine catecholamine determination}

Urine concentrations of noradrenaline were quantified by means of HPLC with electrochemical detection, as previously described (Pestana and Soares-da-Silva, 1994). The lower limits of detection of noradrenaline ranged from 350 to $500 \mathrm{fmol}$.

\section{Measurement of hepatic triglyceride content}

Hepatic triglyceride content was quantified using a Cobas Mira Plus analyzer (ABX Diagnostics) after extraction of lipids from $50 \mathrm{mg}$

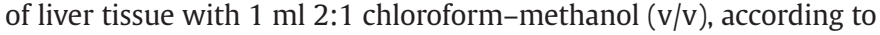
the method by Folch et al. (1957), drying for $\sim 4 \mathrm{~h}$ at $60{ }^{\circ} \mathrm{C}$ and dissolution in $600 \mu$ isopropanol.

\section{Histological analysis}

Hepatic and subcutaneous adipose tissue were fixed for $12-24 \mathrm{~h}$ with $10 \%$ formalin at room temperature, embedded in paraffin, and cut into 4 $\mu \mathrm{m}$-thick sections. Sections were stained with hematoxylin-eosin.

Adipose tissue macrophage and TLR4 immunodetection was performed with an anti-F4/80 monoclonal antibody (CALTAG Laboratories), and a rabbit TLR4 antiserum (Abcam), respectively. In all tissue blocks, $15-20$ different $\times 20$ fields from each of 4 different sections were analyzed. In each field, the number of F4/80-expressing cells was counted, along with the total number of nuclei. Average adipocyte diameter was determined measuring all adipocytes in every field analyzed, using image analysis software (Leica Application System).

\section{Adipose tissue incubations}

The left gonadal fat pads of WT and $\mathrm{CD} 14^{-/-}$mice were dissected under sterile conditions, minced, and incubated in culture medium (1.5 ml of media per gram of tissue) containing DMEM and Ham's F-12 in a $1: 1$ mixture, supplemented with $10 \%(\mathrm{v} / \mathrm{v})$ newborn calf serum that supplies SCD14. The incubation solution also contained $1 \mathrm{nM}$ 3,3',5-triiodo-L-thyronine, $5 \mathrm{mM}$ glutamine, penicillin $(6.35 \mathrm{mg} / \mathrm{l})$ and streptomycin ( $5 \mathrm{mg} / \mathrm{l})$. The time between excision of adipose tissue and initiation of incubation was 15 to $30 \mathrm{~min}$. For each animal, two adipose tissue samples were prepared, with either LPS $(5 \mu \mathrm{g} / \mathrm{ml} ; \gamma$ irradiated lipopolysaccharides from Escherichia coli 0111:B4; Sigma L4391) or the vehicle (Control). The samples were incubated at $37{ }^{\circ} \mathrm{C}$ with an atmosphere of $95 \% \mathrm{O}_{2}$ and $5 \% \mathrm{CO}_{2}$ ( $\mathrm{vol} / \mathrm{vol}$ ) in $1.5 \mathrm{ml}$ aliquots, which were gently swirled every $15 \mathrm{~min}$ for $2 \mathrm{~h}$. The adipose tissue and the supernatant were then quickly frozen and stored at $-80^{\circ} \mathrm{C}$ for later mRNA and protein quantification, respectively.

\section{mRNA quantification}

After collection, samples were quickly immersed in RNAlater (Qiagen) and frozen $\left(-80^{\circ} \mathrm{C}\right)$. Total mRNA was extracted through the 
Table 1

Body composition and fasting plasma glucose of WT and CD14 ${ }^{-/-}$mice after 12 weeks of diet exposure

\begin{tabular}{|c|c|c|c|c|c|c|c|}
\hline Genotype & Diet & Body weight (g) & PWGFP (\% g/g) & Gastrocn. (g) & Liver weight (g) & Tibial length (cm) & FPG (mg/dl) \\
\hline WT & Control & $27.3 \pm 0.82$ & $0.65 \pm 0.13$ & $0.19 \pm 0.064$ & $1.2 \pm 0.19$ & $1.7 \pm 0.08$ & $124 \pm 7.8$ \\
\hline CD14 $4^{-1-}$ & Control & $27.0 \pm 0.99$ & $0.58 \pm 0.11$ & $0.14 \pm 0.036$ & $0.93 \pm 0.059$ & $1.8 \pm 0.07$ & $136 \pm 6.3$ \\
\hline WT & HFHSC & $41.8 \pm 1.64^{*}$ & $2.7 \pm 0.41^{*}$ & $0.20 \pm 0.013$ & $1.2 \pm 0.063$ & $1.8 \pm 0.02$ & $245 \pm 13.7^{*}$ \\
\hline $\mathrm{CD} 14^{-1-}$ & HFHSC & $42.4 \pm 2.53^{*}$ & $2.0 \pm 0.54^{*} \dagger$ & $0.33 \pm 0.097 * \dagger \S$ & $1.3 \pm 0.36^{*}$ & $1.7 \pm 0.06$ & $192 \pm 6.5^{*} \dagger$ \\
\hline
\end{tabular}

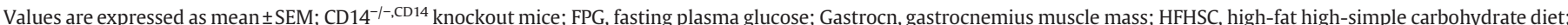
PWGFP, proportional weight of the right gonadal fat pad; WT, C57BL/ 6 mice; ${ }^{*} P<0.05$ vs. Control diet; ${ }^{\dagger} P<0.05$ vs. WT; $§$ significant interaction.

guanidium-thiocyanate selective silica-gel membrane-binding method (Qiagen 74124) according to the manufacturer's instructions. Concentration and purity were assayed by spectrophotometry (Eppendorf 6131000.012). Two-step real-time RT-PCR was used to perform relative quantification of mRNA. For each studied mRNA molecule, standard curves were generated from the correlation between the amount of starting total mRNA and PCR threshold cycle (second derivative maximum method) of graded dilutions from a randomly selected tissue sample $(r>0.97)$. For relative quantification of specific mRNA levels, $50 \mathrm{ng}$ of total mRNA from each sample underwent two-step real-time RT-PCR. A melt curve analysis of each real-time PCR and $2 \%$ agarose gels $(0.5 \mu \mathrm{g} / \mathrm{ml}$ ethidium bromide $)$ were performed to exclude primer-dimer formation and assess the purity of the amplification product. Glyceraldehyde-3-phosphate dehydrogenase (GAPDH) mRNA levels were similar in all experimental groups, which enabled the use of this gene as internal control. Results of mRNA quantification are expressed in an arbitrary unit (AU) set as the average value of WT-Lean group (1 AU), after normalization for GAPDH. RT ( $20 \mu \mathrm{l} ; 10 \mathrm{~min}$ at $22^{\circ} \mathrm{C}, 50 \mathrm{~min}$ at $50^{\circ} \mathrm{C}$ and $10 \mathrm{~min}$ at $95^{\circ} \mathrm{C}$ ) was performed in a standard thermocycler (Whatman Biometra 050901): $40 \mathrm{U} /$ reaction of reverse transcriptase (Invitrogen 18064-014), $20 \mathrm{U} /$ reaction of RNase inhibitor (Promega N2515), $30 \mathrm{ng} / \mathrm{ml}$ random primers (Invitrogen 48190-011), $0.5 \mathrm{mM}$ nucleotide mix (MBI Fermentas R0192), $1.9 \mathrm{mM} \mathrm{MgCl}_{2}$ and $10 \mathrm{mM}$ DTT. Ten percent of the cDNA yield was used as a template for real-time PCR (LightCycler II, Roche) using SYBR green (Qiagen 204143) according to the manufacturer's instructions. Specific PCR primer pairs for the studied genes were: GAPDH-fw 5'-GAG GCC GGT GCT GAG TAT GTC GTG -3' and rev 5'-TCG GCA GAA GGG GCG GAG AT-3'; CD14-fw 5'-GCC TCT CCC GCC CCA CCA G $-3^{\prime}$ and rev 5'-CCG CCG CCG TAC AAT TCC ACA TC-3'; TLR2-fw 5'-ACA GGG ATC CGG GTG GTA AAA AC-3' and rev 5'-GCA GCC GAG GCA AGA ACA AAG A-3'; TLR4-fw 5'-GAT TTA TCC AGG TGT GAA-3' and rev $5^{\prime}-\mathrm{CCT}$ GGG GAA AAA CTC TGG ATA G-3'; TNF- $\alpha-$ fw 5'-AGG GGC CAC CAC GCT CTT CTG TC-3' and rev 5'-GAT GAT CTG AGT GTG AGG GTC TGG-3'.

\section{TNF- $\alpha$ protein quantification}

TNF- $\alpha$ quantification by ELISA was performed in the supernatants of the adipose tissue cultures at the end of the 120 min incubations, according to the manufacturer's instructions (Abcam ab46105).

\section{Statistical analysis}

Data are presented as mean \pm SEM. To assess the effect of genotype and diet for quantitative phenotypes, two-way ANOVA was performed. Statistical significance was set at $P<0.05$.

\section{Results}

\section{Diet-induced obesity in WT and $\mathrm{CD} 14^{-/-}$mice}

Lean WT and $\mathrm{CD}_{14^{-/}}$mice presented similar body weights, PWGFP, adipocyte size, gastrocnemius muscle mass and tibial length (Table 1). However, a trend towards lower liver weight was observed in lean $\mathrm{CD} 14^{-/-}$mice compared with the respective WT group, and obesity was accompanied by a significant increase in liver weight in the transgenic strain.

Exposure to the HFHSC diet was accompanied by progressive obesity in WT mice (Fig. 1A). By 2 weeks the weight differences were already significant and at 12 weeks the weight of obese WT mice was $53 \%$ higher than that of lean WT mice. This was accompanied by increased body fat, as assessed by PWGFP (Table 1) and adipocyte size (Fig. 2A), with no significant differences in gastrocnemius muscle mass, liver weight or tibial length (Table 1 ).

Obesity was also present in CD14 ${ }^{-1-}$ mice fed the HFHSC diet (Fig. 1A). Despite the similar weight gain observed in obese WT and CD14 ${ }^{-1-}$ mice, the transgenic group presented lower PWGFP (Table 1) and adipocyte size (Fig. 2A), and higher gastrocnemius muscle mass (Table 1). This could not be attributed to differences in caloric intake or water ingestion between obese WT and CD14 ${ }^{-/}$groups (Fig. 1B and C).

Attenuation of fasting hyperglycemia and glucose intolerance in obese $\mathrm{CD} 14^{-/-}$mice

Diet-induced obesity was accompanied by fasting hyperglycemia and glucose intolerance in WT and $\mathrm{CD} 14^{-/-}$mice. However, obese $\mathrm{CD}_{14^{-1-}}$ group presented lower fasting plasma glucose (Table 1) and blunted glucose intolerance (Fig. 3), compared to obese WT group. No

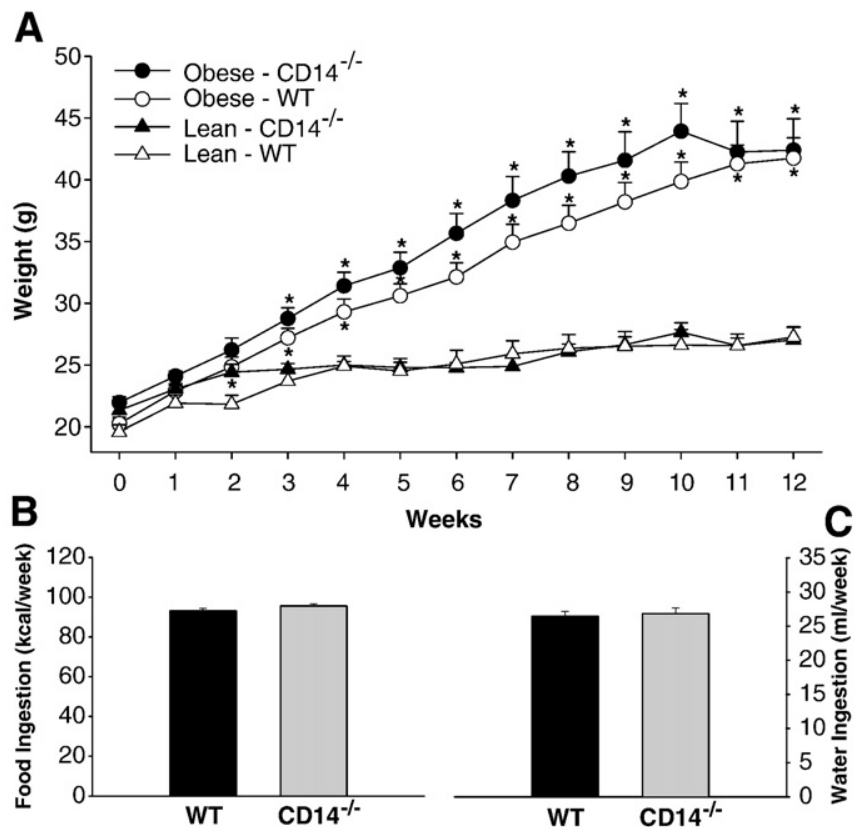

Fig. 1. Body weight, food and water ingestion of obese WT and $\mathrm{CD} 14^{-1-}$ mice. (A) Obesity was induced by ad libitum exposure to a high-fat high-simple carbohydrate (HFHSC) diet for 12 weeks. At the end of the third week, WT and CD14 $4^{-1-}$ mice exposed to the HFHSC diet already presented higher body weights than the respective lean controls. No significant differences were detected in weight gain between obese WT and CD14 ${ }^{-1-}$ groups. This was accompanied by similar food (B) and water $(C)$ ingestion in obese WT and $\mathrm{CD} 14^{-/-}$groups. CD14 ${ }^{-/-}$, CD14 knockout mice; WT, C57BL/6 mice; ${ }^{*} \mathrm{P}<0.05$ vs. Lean. 
A

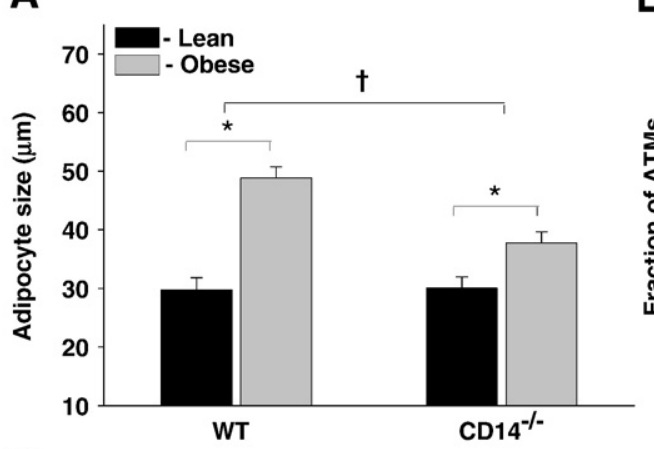

C
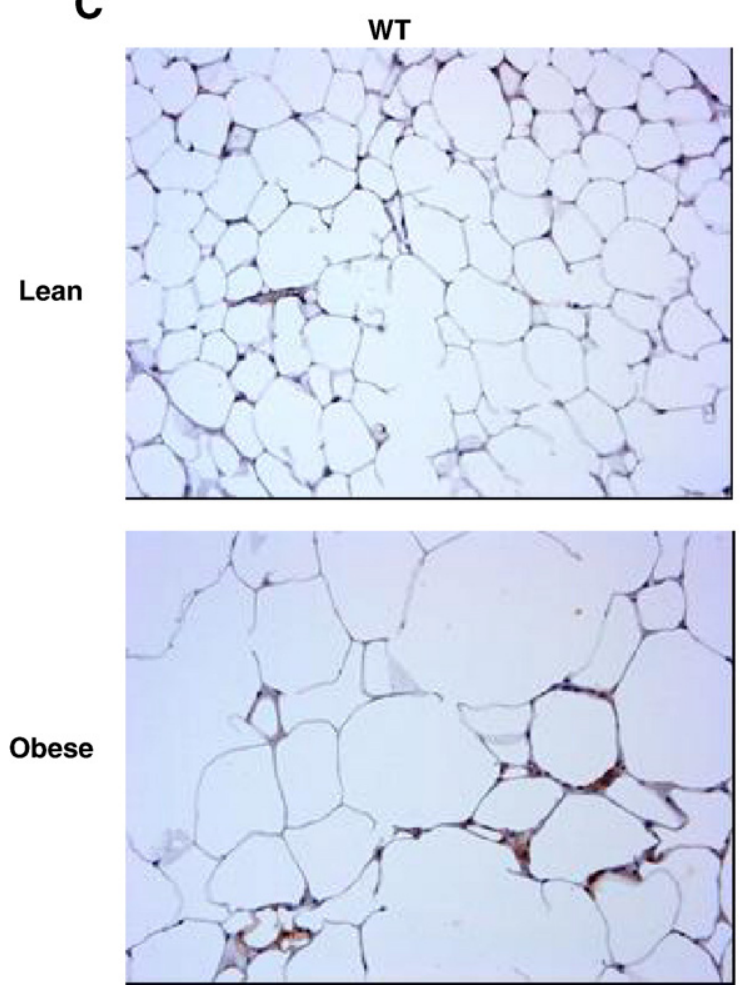

B

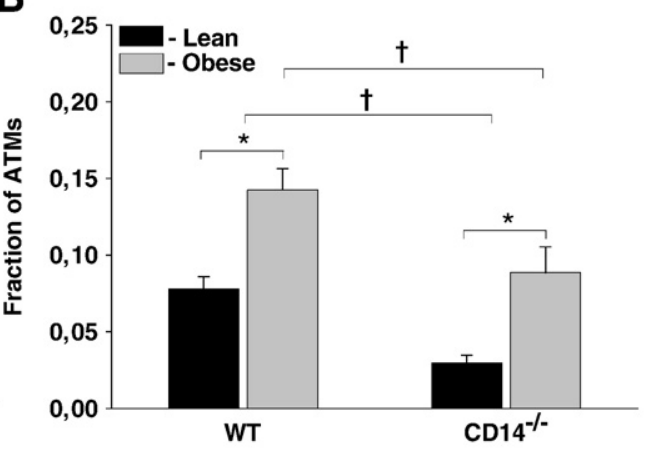

CD14 ${ }^{-/}$
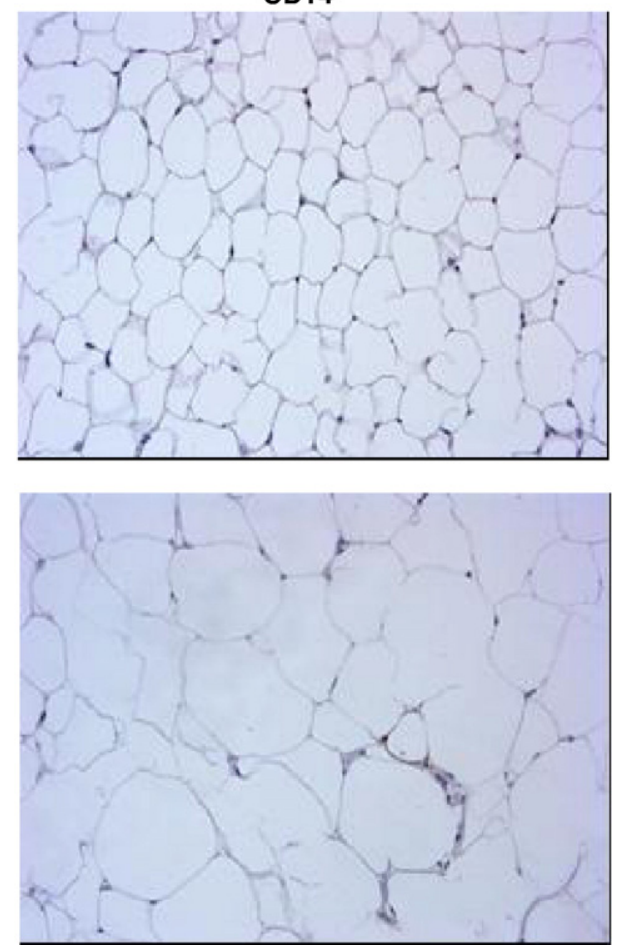

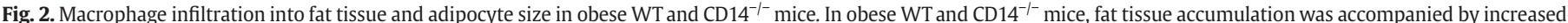

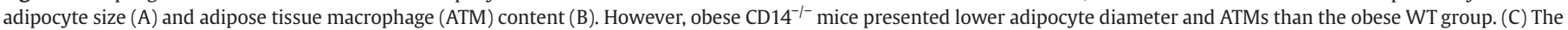

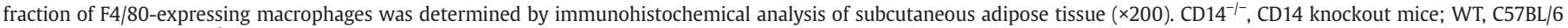
mice; ${ }^{*} P<0.05$ vs. Lean; ${ }^{\dagger} P<0.05$ vs. WT.

significant differences were detected in the glucose tolerance tests between WT and CD14 ${ }^{-/-}$lean mice.

Given that no differences were detected in the insulin resistance tests between lean and obese WT groups (data not shown), we did not compare insulin resistance of WT and $\mathrm{CD} 14^{-/-}$groups.

Hypertension is attenuated in obese $\mathrm{CD} 14^{-/-}$mice

Systolic blood pressure elevation was observed in WT and CD14 ${ }^{-1-}$ mice fed the HFHSC (Fig. 4A). Nevertheless, systolic blood pressures of obese $\mathrm{CD} 14^{-/-}$mice were lower than those of obese WT group.

\section{Blunted sympathetic overactivity in obese $\mathrm{CD} 14^{-/-}$mice}

In WT mice, obesity was accompanied by increased sympathetic activity, as evaluated by the noradrenaline excretion in 24-hour urine (Fig. 4B). In contrast, no significant differences were detected in noradrenaline urinary excretion between lean and obese $\mathrm{CD} 14^{-/-}$ mice.

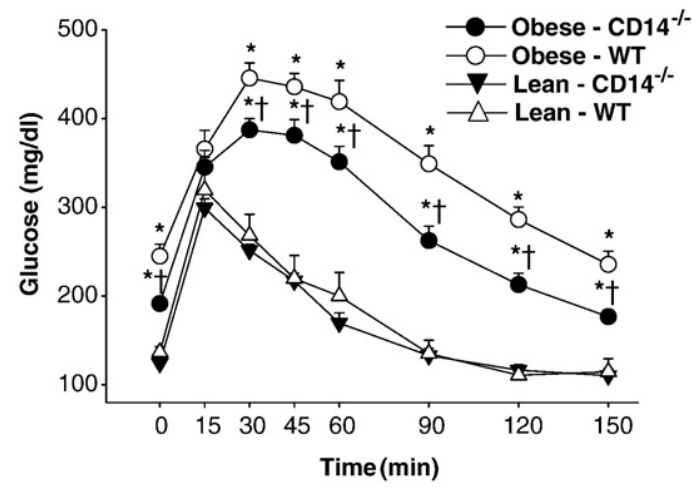

Fig. 3. Glucose homeostasis in WT and $\mathrm{CD} 14^{-/-}$mice. Exposure to the HFHSC diet resulted in impaired glucose homeostasis in both WT and CD14 $14^{-1-}$ mice. However, $\mathrm{CD} 14^{-/-}$obese mice presented lower fasting plasma glucose and blunted glucose intolerance, compared with obese WT mice. No significant differences were detected between WT and CD14 ${ }^{-1-}$ lean groups. CD14 ${ }^{-1-}, \mathrm{CD} 14$ knockout mice; WT, C57BL/6 mice; ${ }^{*} P<0.05$ vs. Lean; ${ }^{\dagger} P<0.05$ vs. WT. 


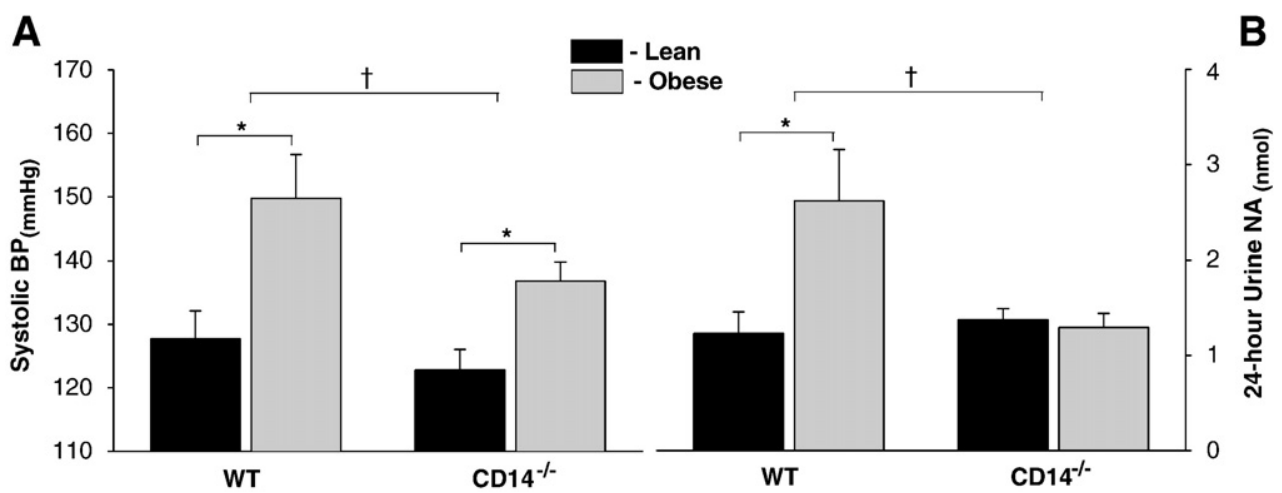

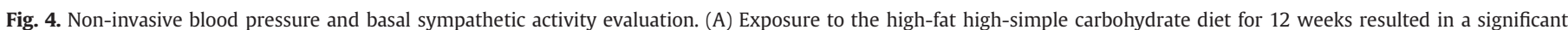

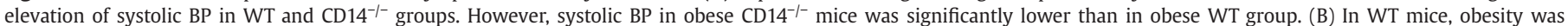

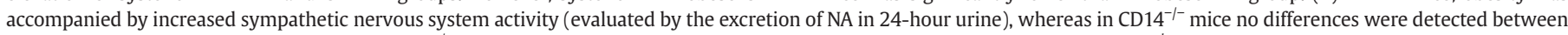
lean and obese groups. BP, blood pressure; $\mathrm{CD} 14^{-1-}, \mathrm{CD} 14$ knockout mice; NA, noradrenaline; WT, C57BL/6 mice; ${ }^{*} \mathrm{P}<0.05$ vs. Lean; ${ }^{\dagger} \mathrm{P}<0.05$ vs. WT.

\section{Attenuation of hepatic steatosis and reduced Kupffer cell content in CD14 ${ }^{-/-}$} mice

Obesity was accompanied by hepatic lipid accumulation in WT and $\mathrm{CD} 14^{-1-}$ mice, as evaluated by liver triglyceride quantification and qualitative histological analysis (Fig. 5A). Hepatic steatosis was attenuated in obese $\mathrm{CD} 14^{-/-}$mice, compared with obese WT group.

Obesity did not significantly affect liver Kupffer cell content, both

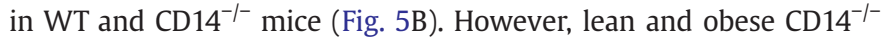
mice presented lower Kupffer cell content than the respective WT groups.
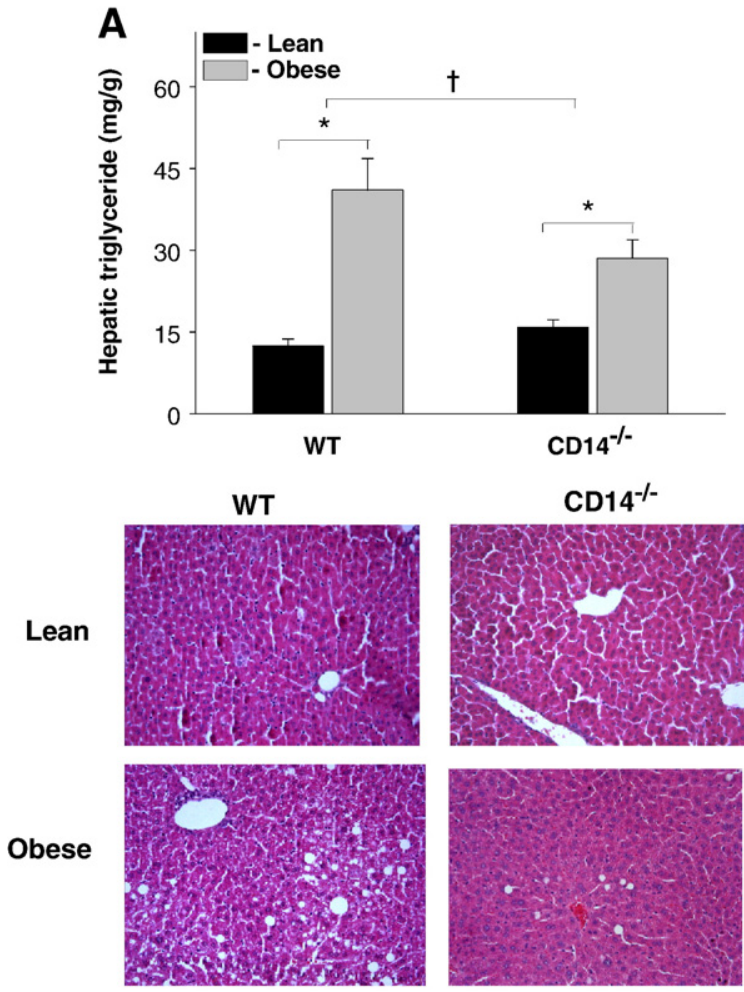

Gene expression profile, TLR4 immunodetection and macrophage infiltration into adipose tissue of obese WT and CD14 ${ }^{-/-}$mice

In WT mice, obesity was accompanied by an upregulation of CD14 and TLR2 gene expression in the liver (Fig. 6). This was paralleled by increased TLR4 mRNA levels in visceral fat and by enhanced TLR2 expression in subcutaneous fat. In obese CD14 ${ }^{-1-}$ mice, TLR4 gene activation was present in both subcutaneous and visceral fat, whereas TLR2 upregulation was restricted to the subcutaneous fat.

In obese mice, macrophage infiltration into adipose tissue was observed in WT and $\mathrm{CD} 14^{-/-}$groups (Fig. 2B). However, the macrophage
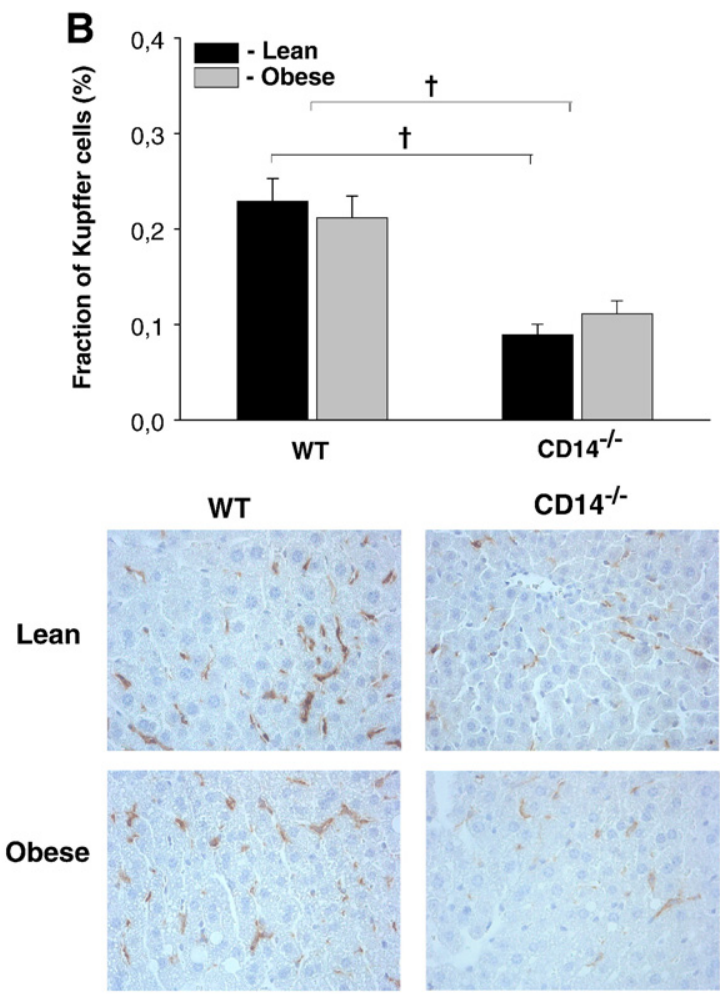

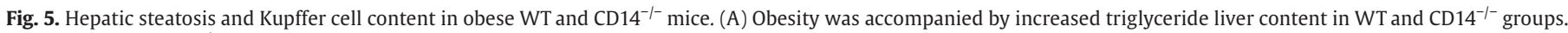

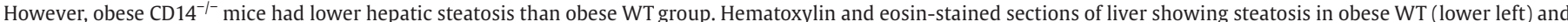

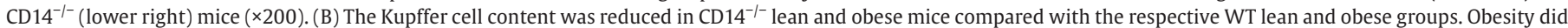

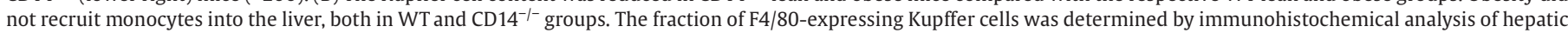
tissue $(\times 400)$. CD14 ${ }^{-1-}, \mathrm{CD} 14$ knockout mice; WT, C57BL/ 6 mice; ${ }^{*} P<0.05$ vs. Lean; ${ }^{\dagger} P<0.05$ vs. WT. 

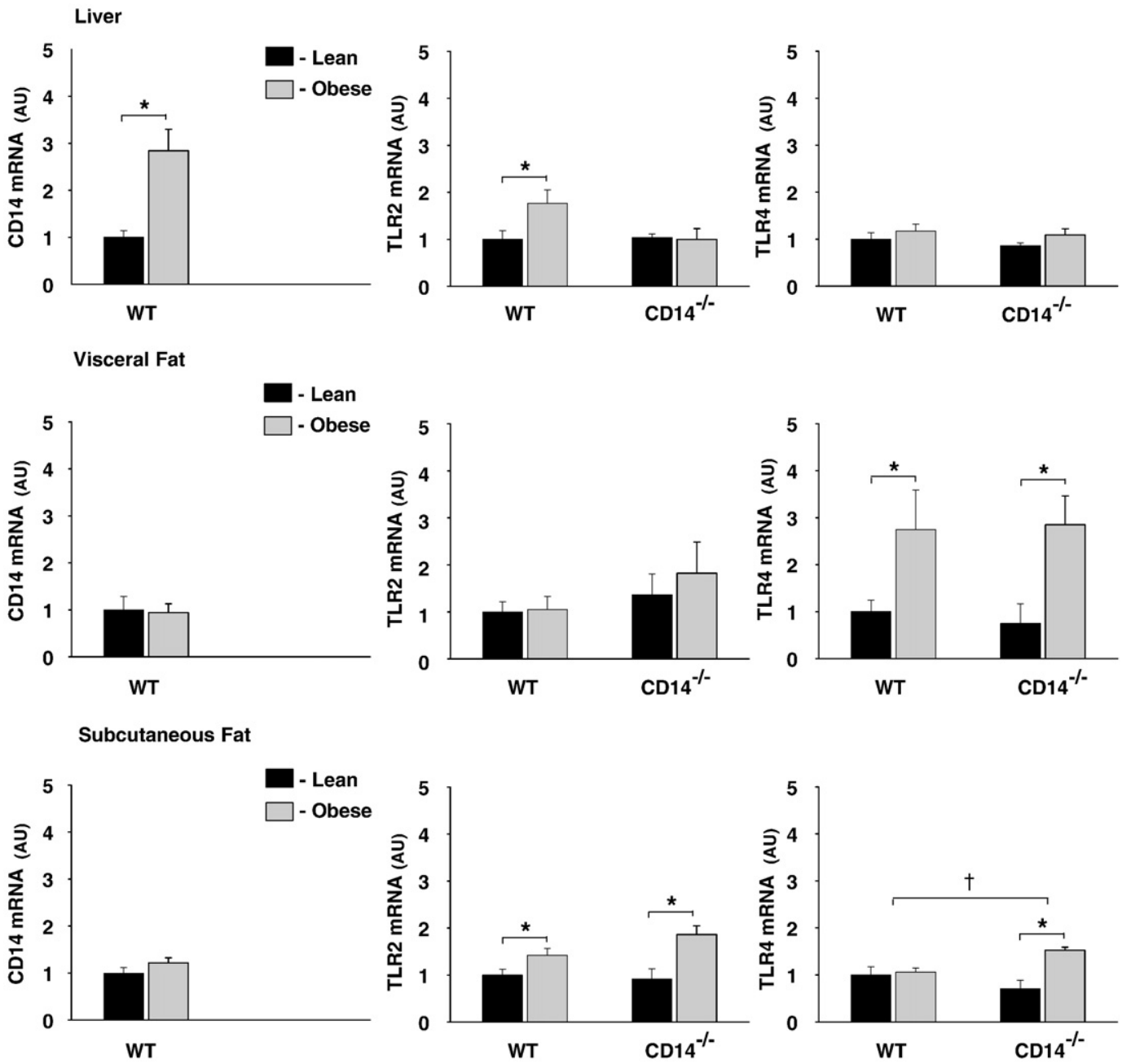

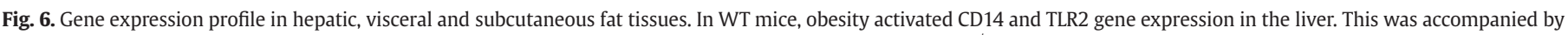

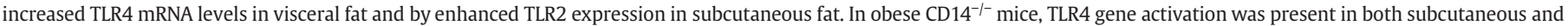
visceral fat, and TLR2 mRNA levels were enhanced in subcutaneous fat. CD14 ${ }^{-/-}$, CD14 knockout mice; WT, C57BL/6 mice; ${ }^{*}<0.05$ vs. Lean; ${ }^{\dagger} P<0.05$ vs. WT.

content of subcutaneous fat in lean and obese $\mathrm{CD} 14^{-/-}$mice was reduced compared with the respective WT groups.

Subcutaneous fat TLR4 immunostaining revealed TLR4 expression both in adipose tissue macrophages and adipocytes, being less pronounced in the latter. This occurred in both WT and CD14 ${ }^{-1-}$ mice, in lean and obese groups (Fig. 7).

\section{LPS-induced TLR4 activation in subcutaneous fat tissues}

In order to evaluate the integrity of TLR4 signaling pathways in both WT and $\mathrm{CD} 14^{-/-}$mice, subcutaneous fat tissues were incubated with the TLR4 agonist LPS, in a culture medium containing exogenous sCD14 (Fig. 8). In obese WT group, 120 min incubation of fat tissue with LPS resulted in a two-fold increase of TLR2 mRNA levels, whereas in lean WT group it did not significantly change TLR2 gene expression. TNF- $\alpha$ mRNA expression in adipose tissue and protein levels in the adipose tissue culture supernatants increased after incubation with LPS in obese WT mice.

A similar pattern of LPS-induced gene activation was observed in CD14 ${ }^{-/-}$mice. In fact, LPS-induced TLR2 and TNF- $\alpha$ mRNA upregulation was restricted to the obese group.

\section{Discussion}

In the present study, obesity was accompanied by enhanced TLR4 gene expression and activity in adipose tissues. In fact, obese WT mice presented higher TLR4 mRNA levels and enhanced LPS-induced proinflammatory gene activation in adipose tissues, compared with lean WT group. These results are in agreement with previous reports showing TLR4 upregulation in fat tissues of genetically obese mice as well as in mouse models of diet-induced obesity (Lin et al., 2000; Shi et al., 2006). Of note, TLR4 and TLR2 were differently regulated: TLR4 gene upregulation was restricted to the visceral fat of obese WT mice, while TLR2 mRNA levels were elevated in the liver and subcutaneous fat. This could be relevant given the accumulating data implicating TLR2-mediated signaling in the metabolic complications of obesity. In a recent study, Senn demonstrated that TLR2 is essential for the development of free fatty acid-induced insulin resistance (Senn, 2006). Moreover, TLR2 synthesis in both adipocytes and hepatocytes was shown to be strongly induced by TLR4 signaling (Lin et al., 2000), and could mediate the enhanced inflammatory response under inflammatory conditions (Senn, 2006). A three-fold increase of CD14 mRNA levels was also observed in the liver of obese WT mice. In a recent report, LPS circulating levels were found to be increased by 2-3 times in mice exposed to a high-fat diet, a threshold that was designated 'metabolic endotoxemia' (Cani et al., 2007). Given that the liver is the main source of the LPS ligand SCD14, it is tempting to speculate that CD14 upregulation in the hepatic tissue of obese WT mice might play a role in TLR4 activation induced by 'metabolic endotoxemia'.

Interestingly, TLR4 and TLR2 gene activation was observed in obese mice lacking CD14, and immunodetection showed presence of TLR4 in 


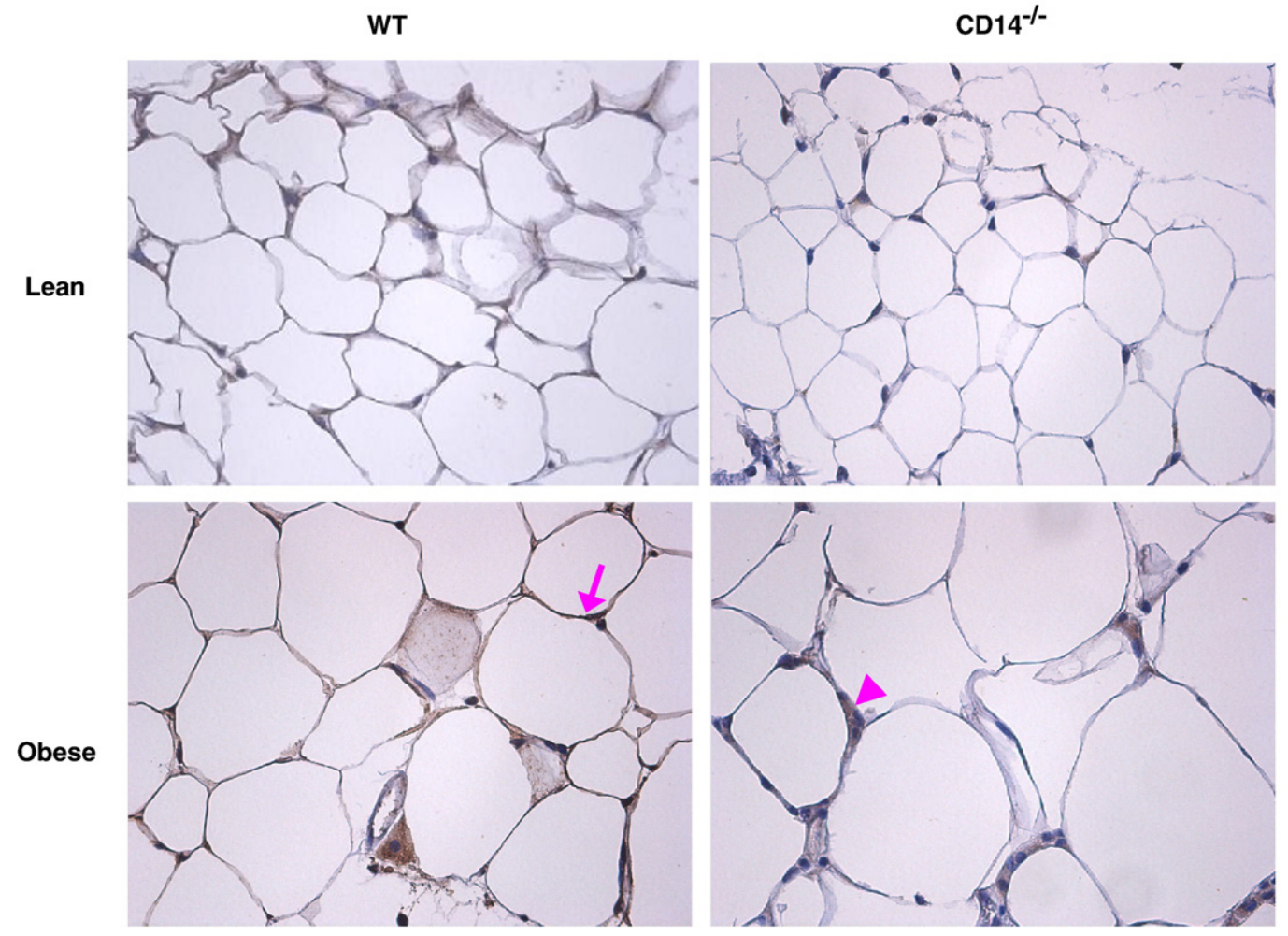

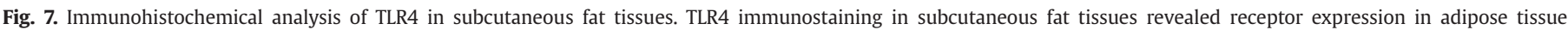

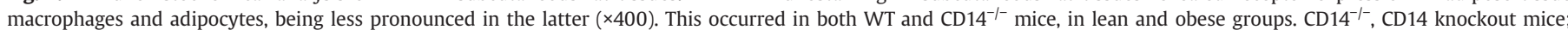

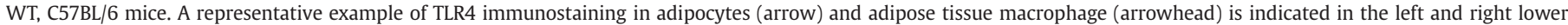
panels, respectively.

both adipocytes and macrophages in subcutaneous adipose tissue of CD $14^{-1-}$ mice. Furthermore, in the presence of exogenous SCD14, LPSinduced TLR4 activation in subcutaneous fat tissues of CD14 ${ }^{-/-}$obese mice was also preserved. These results suggest intact TLR signaling pathways in $\mathrm{CD} 14^{-/-}$mice, so that differences in phenotype between WT and $\mathrm{CD} 14^{--}$mice could solely be attributed to impaired CD14dependent TLR activation. This could be particularly relevant, given that it remains to be determined if there are CD14-independent but TLR4- or TLR2-dependent responses in obesity. Namely, it is still not known if TLR4 and TLR2 activation by nutritional fatty acids in obesity is mediated by CD14 (Lee and Hwang, 2006). Of note, CD14independent and TLR4-dependent responses have already been described in such different contexts as bacterial infection (Viriyakosol et al., 2006) and leukocyte-endothelial interactions (Andonegui et al., 2002).

CD14 ${ }^{-/}$mice exposed to the HFHSC diet showed similar weight gain but lower adiposity and higher muscle mass than obese WT group. The results agree well with a previous work reporting that this transgenic strain has low body fat and gains less adiposity with aging, while showing increased lean body mass (Johnson et al., 2004). Moreover, the adipose tissue of $\mathrm{CD} 14^{-/-}$mice presented lower macrophage content than their WT counterparts. This could have influenced the phenotype of the transgenic animals, given that monocyte infiltration into adipose tissues has been implicated in the low-grade chronic inflammatory state of obesity (Di Gregorio et al., 2005; Weisberg et al., 2003). In fact, obese mice lacking either the C-C motif chemokine receptor-2 (CCR2) or the CCR2 ligand monocyte chemoattractant protein-1 (MCP-1) have reduced macrophage infiltration into adipose tissue, with reduced inflammatory activation and blunted metabolic complications (Kanda et al., 2006; Weisberg et al., 2006).

In WT mice, obesity was accompanied by sympathetic nervous system activation, as evaluated by the excretion of noradrenaline in 24-hour urine. Sympathetic overactivity has been consistently reported in both animal models and human obesity, and has been proposed to underlie blood pressure elevation in this disease (Lembo et al., 1992; Tentolouris et al., 2006). In fact, several experimental and clinical studies showed a positive correlation between the urinary excretion of noradrenaline and hypertension (Aneja et al., 2004). In our study, obesity was not accompanied by sympathetic overactivity in CD14 knockout mice, with hypertension being attenuated in this experimental group. High-fat feeding has been recently shown to increase plasma LPS by 2-3 times in mice, a threshold defined as 'metabolic endotoxemia' (Cani et al., 2007). It has also been demonstrated that peripherally administered LPS enhances noradrenaline biosynthesis in the mouse locus ceruleus (Ota et al., 2007). Given the central role of this brain stem nucleus in stress-induced sympathetic activation, 'metabolic endotoxemia' could represent a stimulus for sympathetic overactivity in obesity, through a CD14 dependent pathway in the central nervous system.

Exposure of the WT mice to the HFHSC diet for 12 weeks was accompanied by alterations in glucose homeostasis, with elevated fasting plasma glucose and glucose intolerance. However, obese WT mice did not show insulin resistance. These results are in agreement with previous reports showing that short-term high-fat feeding in C57BL/6 mice could affect insulin sensitivity and glucose tolerance independently. This mouse strain shows glucose intolerance despite relatively good insulin sensitivity of peripheral tissues early in dietinduced obesity (Rossmeisl et al., 2003), whereas insulin resistance has been consistently reported after 6 months of HFHSC diet exposure (Surwit et al., 1988). Although obesity also impaired glucose homeostasis in $\mathrm{CD} 14^{-/-}$mice, fasting plasma glucose was lower and glucose intolerance was attenuated compared to obese WT mice. These results are in agreement with previous studies showing blunted type 2 diabetes mellitus in TLR4 ${ }^{-/-}$and $\mathrm{CD} 14^{-/-}$obese mice exposed to highfat diets (Cani et al., 2007; Shi et al., 2006). 
WT

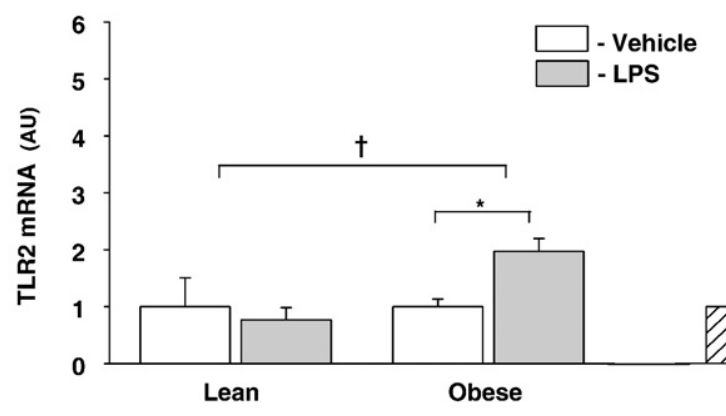

WT
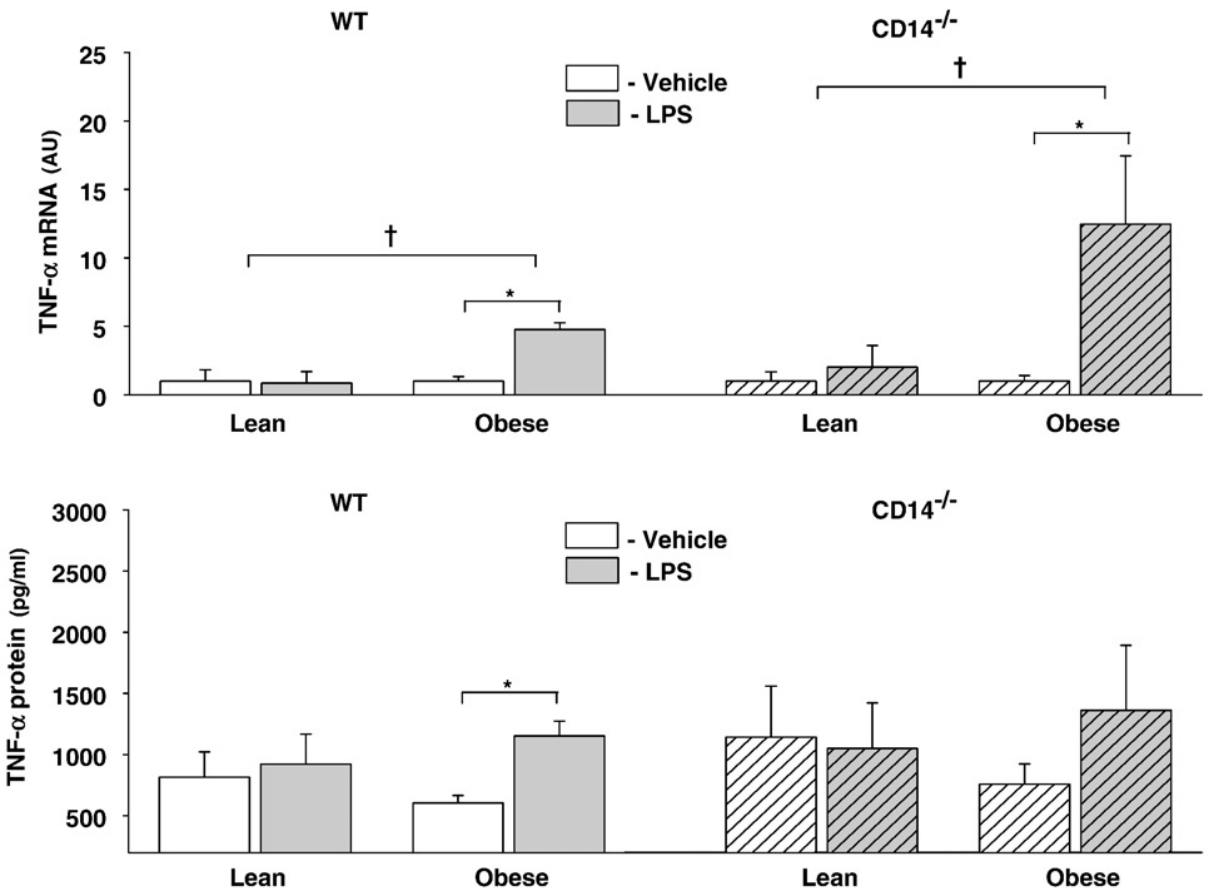

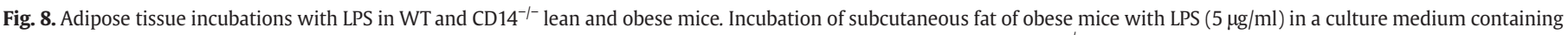

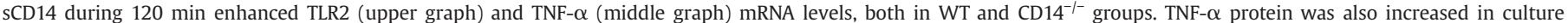

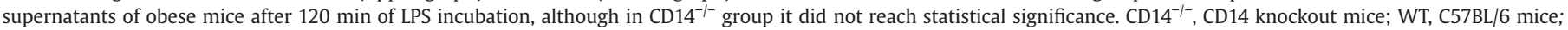
${ }^{*} P<0.05$ vs. Vehicle; ${ }^{\dagger} P<0.05$ vs. Lean.

In our study, liver CD14 mRNA levels were increased in obese WT mice and CD14 inhibition was accompanied by a reduction in hepatic steatosis and liver Kupffer cell content. Moreover, liver TLR2 upregulation in obesity was restricted to the WT group. This could be relevant, given the established role of innate immunity and Kupffer cell activation in the progression of non alcoholic steatosis to steatohepatitis and fibrosis (Kolios et al., 2006; Tomita et al., 2006). In obesity, enhanced intestinal mucosa permeability with increased portal LPS has been proposed to underlie non-alcoholic fatty liver disease (Brun et al., 2007). In fact, $o b / o b$ and $d b / d b$ mice have decreased intestinal resistance with enhanced LPS-induced pro-inflammatory and fibrogenic responses in hepatic stellate cells, which present higher mCD14 expression. Moreover, in the methionine-choline deficient diet-induced model of nonalcoholic steatohepatitis, TLR4-mediated liver injury and inflammatory cytokine induction are enhanced (Szabo et al., 2005).

Finally, it should be mentioned that the attenuation of the cardiovascular and metabolic complications of obesity in mice lacking CD14 could have been mediated by adipokines. Although this hypothesis was not specifically addressed in the present study, a large body of evidence supports a critical role of adipokines such as leptin, adiponectin, resistin and visfatin in the pathophysiology of obesity (Ahima and Osei, 2008). Moreover, several studies have described interplays between TLR signaling and adipokines. In a recent report, significant upregulation of TLR 1 to -9 expression in preadipocytes and adipocytes of ob/ob and $\mathrm{db} / \mathrm{db}$ mice was demonstrated, revealing a strong regulation of TLR expression by leptin (Batra et al., 2007). In a different study, adiponectin has been shown to negatively regulate macrophage-like cell response to TLR ligands (Yamaguchi et al., 2005).

In conclusion, CD14 inhibition resulted in lower adiposity and hepatic steatosis, improved glucose homeostasis, blunted sympathetic overactivity and reduced blood pressure elevation of obese mice exposed to a HFHSC diet. This was observed in the presence of preserved TLR4 and TLR2 gene expression, and intact TLR4 signaling pathways. The results of the present study suggest a role for CD14dependent TLR activation in the cardiovascular and metabolic complications of obesity, and could contribute for the establishment of novel therapeutic targets in the metabolic syndrome.

\section{Acknowledgments}

We are sincerely grateful to Antónia Teles and Marta Oliveira, for their expert technical support. Supported by grants from the Fundação para a Ciência e Tecnologia (POCTI/SAU-MMO/61547/2004 and POCI/ SAU-OBS/55288/2004; partially funded by FEDER), through the Cardiovascular R\&D (51/94-FCT, Portugal) and Nephrology R\&D (725/04-FCT, Portugal) Units. 


\section{References}

Ahima, R.S., Osei, S.Y., 2008. Adipokines in obesity. Frontiers of Hormone Research 36, 182-197.

Akira, S., 2003. Toll-like receptor signaling. The Journal of Biological Chemistry 278 (40), 38105-38108.

Andonegui, G., Goyert, S.M., Kubes, P., 2002. Lipopolysaccharide-induced leukocyteendothelial cell interactions: a role for CD14 versus toll-like receptor 4 within microvessels. Journal of Immunology 169 (4), 2111-2119.

Aneja, A., El-Atat, F., McFarlane, S.I., Sowers, J.R., 2004. Hypertension and obesity. Recent Progress in Hormone Research 59, 169-205.

Batra, A., Pietsch, J., Fedke, I., Glauben, R., Okur, B., Stroh, T., Zeitz, M., Siegmund, B., 2007. Leptin-dependent toll-like receptor expression and responsiveness in preadipocytes and adipocytes. The American Journal of Pathology 170 (6), 1931-1941.

Brun, P., Castagliuolo, I., Di Leo, V., Buda, A., Pinzani, M., Palu, G., Martines, D., 2007. Increased intestinal permeability in obese mice: new evidence in the pathogenesis of nonalcoholic steatohepatitis. American Journal of Physiology: Gastrointestinal and Liver Physiology 292 (2), G518-G525.

Cani, P.D., Amar, J., Iglesias, M.A., Poggi, M., Knauf, C., Bastelica, D., Neyrinck, A.M., Fava, F., Tuohy, K.M., Chabo, C., Waget, A., Delmee, E., Cousin, B., Sulpice, T., Chamontin, B. Ferrieres, J., Tanti, J.F., Gibson, G.R., Casteilla, L., Delzenne, N.M., Alessi, M.C., Burcelin, R., 2007. Metabolic endotoxemia initiates obesity and insulin resistance. Diabetes 56 (7), 1761-1772.

Di Gregorio, G.B., Yao-Borengasser, A., Rasouli, N., Varma, V., Lu, T., Miles, L.M., Ranganathan, G., Peterson, C.A., McGehee, R.E., Kern, P.A., 2005. Expression of CD68 and macrophage chemoattractant protein-1 genes in human adipose and muscle tissues: association with cytokine expression, insulin resistance, and reduction by pioglitazone. Diabetes 54 (8), 2305-2313.

Folch, J., Lees, M., Sloane Stanley, G.H., 1957. A simple method for the isolation and purification of total lipides from animal tissues. The Journal of Biological Chemistry 226 (1), 497-509.

Johnson, G.B., Riggs, B.L., Platt, J.L., 2004. A genetic basis for the "Adonis" phenotype of low adiposity and strong bones. FASEB Journal 18 (11), 1282-1284.

Kanda, H., Tateya, S., Tamori, Y., Kotani, K., Hiasa, K., Kitazawa, R., Kitazawa, S., Miyachi, H. Maeda, S., Egashira, K., Kasuga, M., 2006. MCP-1 contributes to macrophage infiltration into adipose tissue, insulin resistance, and hepatic steatosis in obesity. The Journal of Clinical Investigation 116 (6), 1494-1505.

Kirschning, C.J., Wesche, H., Merrill Ayres, T., Rothe, M., 1998. Human toll-like receptor 2 confers responsiveness to bacterial lipopolysaccharide. The Journal of Experimental Medicine 188 (11), 2091-2097.

Kolios, G., Valatas, V., Kouroumalis, E., 2006. Role of Kupffer cells in the pathogenesis of liver disease. World Journal of Gastroenterology 12 (46), 7413-7420.

Lee, J.Y., Hwang, D.H., 2006. The modulation of inflammatory gene expression by lipids: mediation through Toll-like receptors. Molecules and Cells 21 (2), 174-185.

Lee, J.Y., Ye, J., Gao, Z., Youn, H.S., Lee, W.H., Zhao, L., Sizemore, N., Hwang, D.H., 2003. Reciprocal modulation of Toll-like receptor-4 signaling pathways involving MyD88 and phosphatidylinositol 3-kinase/AKT by saturated and polyunsaturated fatty acids. The Journal of Biological Chemistry 278 (39), 37041-37051.

Lembo, G., Napoli, R., Capaldo, B., Rendina, V., Iaccarino, G., Volpe, M., Trimarco, B., Sacca, L., 1992. Abnormal sympathetic overactivity evoked by insulin in the skeletal muscle of patients with essential hypertension. The Journal of Clinical Investigation 90 (1), 24-29.

Lin, Y., Lee, H., Berg, A.H., Lisanti, M.P., Shapiro, L., Scherer, P.E., 2000. The lipopolysaccharideactivated toll-like receptor (TLR)-4 induces synthesis of the closely related receptor TLR-2 in adipocytes. The Journal of Biological Chemistry 275 (32), 24255-24263.

Means, T.K., Lien, E., Yoshimura, A., Wang, S., Golenbock, D.T., Fenton, M.J., 1999. The CD14 ligands lipoarabinomannan and lipopolysaccharide differ in their requirement for Toll-like receptors. Journal of Immunology 163 (12), 6748-6755.

Mills, E., Kuhn, C.M., Feinglos, M.N., Surwit, R., 1993. Hypertension in CB57BL/6J mouse model of non-insulin-dependent diabetes mellitus. American Journal of Physiology 264 (1 Pt 2), R73-R78.
Ota, A., Kaneko, Y.S., Mori, K., Nakashima, A., Nagatsu, I., Nagatsu, T., 2007. Effect of peripherally administered lipopolysaccharide (LPS) on GTP cyclohydrolase I, tetrahydrobiopterin and norepinephrine in the locus coeruleus in mice. Stress 10 (2), 131-136.

Pestana, M., Soares-da-Silva, P., 1994. Effect of type A and B monoamine oxidase selective inhibition by Ro 41-1049 and Ro 19-6327 on dopamine outflow in rat kidney slices. British Journal of Pharmacology 113 (4), 1269-1274.

Pugin, J., Heumann, I.D., Tomasz, A., Kravchenko, V.V., Akamatsu, Y., Nishijima, M., Glauser, M.P., Tobias, P.S., Ulevitch, R.J., 1994. CD14 is a pattern recognition receptor. Immunity 1 (6), 509-516.

Rogers, P., Webb, G.P., 1980. Estimation of body fat in normal and obese mice. British Journal of Nutrition 43 (1), 83-86.

Rossmeisl, M., Rim, J.S., Koza, R.A., Kozak, L.P., 2003. Variation in type 2 diabetes-related traits in mouse strains susceptible to diet-induced obesity. Diabetes 52 (8),1958-1966.

Semenkovich, C.F., 2006. Insulin resistance and atherosclerosis. The Journal of Clinical Investigation 116 (7), 1813-1822.

Senn, J.J., 2006. Toll-like receptor-2 is essential for the development of palmitateinduced insulin resistance in myotubes. The Journal of Biological Chemistry 281 (37), 26865-26875.

Shi, H., Kokoeva, M.V., Inouye, K., Tzameli, I., Yin, H., Flier, J.S., 2006. TLR4 links innate immunity and fatty acid-induced insulin resistance. The Journal of Clinical Investigation 116 (11), 3015-3025.

Song, M.J., Kim, K.H., Yoon, J.M., Kim, J.B., 2006. Activation of Toll-like receptor 4 is associated with insulin resistance in adipocytes. Biochemical and Biophysical Research Communications 346 (3), 739-745.

Surwit, R.S., Kuhn, C.M., Cochrane, C., McCubbin, J.A., Feinglos, M.N., 1988. Diet-induced type II diabetes in C57BL/6J mice. Diabetes 37 (9), 1163-1167.

Szabo, G., Velayudham, A., Romics Jr., L., Mandrekar, P., 2005. Modulation of nonalcoholic steatohepatitis by pattern recognition receptors in mice: the role of tolllike receptors 2 and 4. Alcoholism, Clinical and Experimental Research 29 (11 Suppl), 140S-145S.

Tentolouris, N., Liatis, S., Katsilambros, N., 2006. Sympathetic system activity in obesity and metabolic syndrome. Annals of the New York Academy of Sciences 1083, 129-152.

Tomita, K., Tamiya, G., Ando, S., Ohsumi, K., Chiyo, T., Mizutani, A., Kitamura, N., Toda, K., Kaneko, T., Horie, Y., Han, J.Y., Kato, S., Shimoda, M., Oike, Y., Tomizawa, M., Makino, S, Ohkura, T., Saito, H., Kumagai, N., Nagata, H., Ishii, H., Hibi, T., 2006. Tumour necrosis factor alpha signalling through activation of Kupffer cells plays an essential role in liver fibrosis of non-alcoholic steatohepatitis in mice. Gut 55 (3), 415-424.

Viriyakosol, S., Matthias, M.A., Swancutt, M.A., Kirkland, T.N., Vinetz, J.M., 2006. Toll-like receptor 4 protects against lethal Leptospira interrogans serovar icterohaemorrhagiae infection and contributes to in vivo control of leptospiral burden. Infection and Immunity 74 (2), 887-895.

Weisberg, S.P., McCann, D., Desai, M., Rosenbaum, M., Leibel, R.L., Ferrante Jr., A.W 2003. Obesity is associated with macrophage accumulation in adipose tissue. The Journal of Clinical Investigation 112 (12), 1796-1808.

Weisberg, S.P., Hunter, D., Huber, R., Lemieux, J., Slaymaker, S., Vaddi, K., Charo, I., Leibel, R.L Ferrante Jr., A.W., 2006. CCR2 modulates inflammatory and metabolic effects of highfat feeding. The Journal of Clinical Investigation 116 (1), 115-124.

Wright, S.D., Ramos, R.A., Tobias, P.S., Ulevitch, R.J., Mathison, J.C., 1990. CD14, a receptor for complexes of lipopolysaccharide (LPS) and LPS binding protein. Science 249 (4975), 1431-1433.

Yamaguchi, N., Argueta, J.G., Masuhiro, Y., Kagishita, M., Nonaka, K., Saito, T., Hanazawa, S, Yamashita, Y., 2005. Adiponectin inhibits Toll-like receptor family-induced signaling. FEBS Letters 579 (30), 6821-6826.

Yang, R.B., Mark, M.R., Gray, A., Huang, A., Xie, M.H., Zhang, M., Goddard, A., Wood, W.I., Gurney, A.L., Godowski, P.J., 1998. Toll-like receptor-2 mediates lipopolysaccharideinduced cellular signalling. Nature (6699), 284-288. 